\title{
Is there a body protein reserve?
}

\section{By J. S. Garrow, Clinical Research Centre, Watford Road, Harrow, Middlesex $H A$ I $3 U \mathcal{F}$}

With modern parenteral techniques it is possible to supply all nutrients for long periods in adequate, or even excessive, amounts. However, this therapeutic power involves costs. The financial cost involved in providing the parenteral solution prepared to very high specifications, and the staff and apparatus to administer it, is not negligible. The clinician may be more concerned with the cost to the patient in terms of increased risk of infection, and the possible toxicity of antibiotics given to treat or prevent that infection. It is, therefore, necessary to judge if the benefit to a given patient of parenteral nutrition outweighs the risks associated with the insertion of a central venous catheter. In making this decision the concept of nutrient stores in the body play a crucial role.

Some authors imply, or explicitly state, that there are no significant nutrient reserves in the body. 'Where the ability to ingest, digest or absorb the nutrients is defective, and the patient seems likely to deteriorate, then recourse should be made at once to the intravenous route. Indeed steps should already have been taken to anticipate this happening by providing access to the circulation for complete parenteral nutrition. But it should also be appreciated that the well-nourished casualty can survive for a few days on glucose and electrolytes, provided serious blood loss is replaced' (Cuthbertson, r 980 ). This statement by the doyen of trauma-nutritionists alarms me. If this philosophy is accepted the great majority of patients undergoing surgery will be subjected to the dangers of central-vein catheterization. The reported incidence of catheter sepsis varies, but $7 \%$ has been described as an 'acceptable rate' (Wilmore, 1980). The advice for urgent use of parenteral nutrition arises from the belief that there is no body reserve of protein. 'Unlike carbohydrate which is in limited reserve as glycogen, and fat which has an almost unlimited reserve, there is no reserve of protein. Every molecule is performing a vital function,...' (Blackburn \& Kaminski, I980). This statement cannot be literally true, but it highlights the need to establish how much protein a person can afford to lose before replacement of nitrogen by parenteral nutrition becomes a preferable option. To answer this question we can study four models of protein depletion.

\section{Experimentally protein-depleted dog}

During the I930s many studies were made on the effects of total starvation, or prolonged restriction of dietary protein, on protein metabolism in the dog. This literature has been well reviewed by Keys et al. (1950). The work of Weech and his colleagues showed that after $80 \mathrm{~d}$ on a protein-deficient diet of carrots, rice, lard and sugar a dog lost approximately $20 \%$ of initial body-weight, approximately 
$28 \%$ of body protein, but nearly $70 \%$ of serum albumin. This striking loss of albumin occurred rapidly at first; approximately $40 \%$ was lost in the first $20 \mathrm{~d}$ of protein restriction, and thereafter the rate of loss of albumin slowed to parallel that of other proteins. Whipple et al. (1947) postulated an adaptive response to protein depletion by which tissue proteins were raided to form plasma protein and haemoglobin, and suggested that the premortal rise in urinary nitrogen, which was often seen in the terminal stages of protein depletion, represented a breakdown in the mechanism for albumin synthesis. This suggestion was of great interest to those concerned with the clinical problem of protein-energy malnutrition in children, who also show severe hypoalbuminaemia, and who seem to reach an irreversible phase of protein depletion in which the capacity for protein synthesis is lost, even when an adequate diet is provided.

In the early r 950 s tracer techniques for in vivo studies of protein metabolism were in their infancy, but it seemed reasonable to test Whipple's hypothesis by giving ${ }^{35}$ S-labelled methionine to malnourished children, and measuring incorporation into albumin, in the hope of detecting those children who had reached the stage of impaired albumin synthesis (Garrow, 1957). This naive plan produced results which defied interpretation; the more severely depleted the child the greater the incorporation into plasma protein of the radioactive label, but some results did not fit even this pattern. The late $\mathrm{Dr} \mathrm{J}$. B. Allison allowed me to repeat

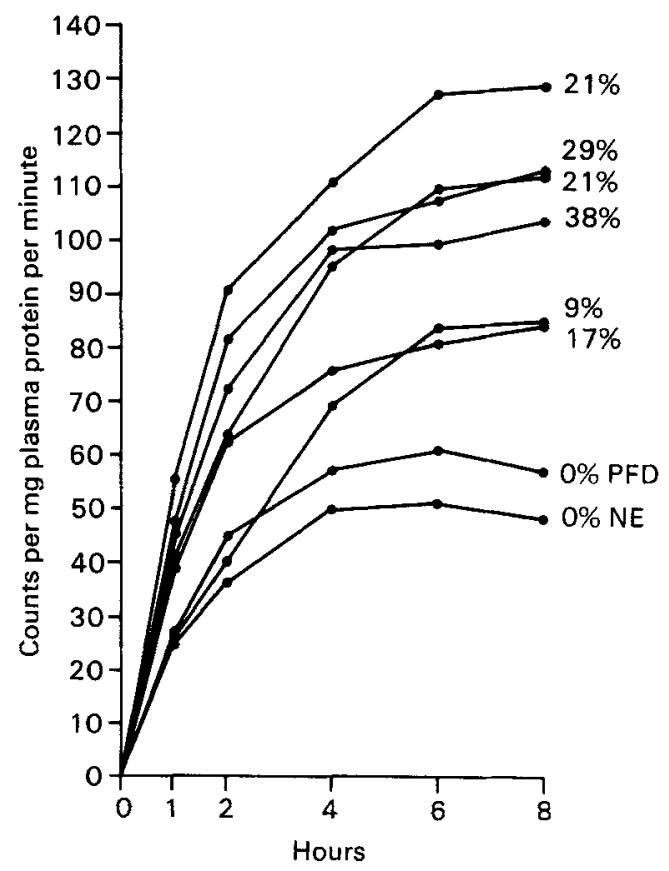

Fig. I. Incorporation of ${ }^{35} \mathrm{~S}$-methionine into plasma protein of dogs following a single intravenous injection. Percentage loss of total body protein before injection (achieved by feeding protein-free diet and plasmapheresis) is indicated for each curve. NE shows dog before depletion on diet maintaining nitrogen equilibrium. PFD indicates dog started on protein-free diet on the same day as the injection (Garrow, r959). 
the experiments on dogs in his laboratory which were maintained on a protein-free diet for periods up to $68 \mathrm{~d}$. In some dogs protein depletion was made more severe by plasmapheresis. The results of the study are summarized in Fig. I. In normal dogs a standard dose of label produced a peak labelling about $6 \mathrm{~h}$ after injection of $45 \mathrm{cpm} / \mathrm{mg}$ plasma protein. With progressive protein depletion the peak value increased to a maximum of $130 \mathrm{cpm} / \mathrm{mg}$ protein when the dog had lost about $21 \%$ of total body protein, after about $30 \mathrm{~d}$ on the protein-free diet. With continuing depletion no further increase occurred, and two very severely depleted dogs, who died I week after injection, showed a slightly decreased uptake in plasma protein (Garrow, 1959).

These results cannot be interpreted in a quantitative way, because the pool sizes and specific activity of precursor were not accurately measured in this very simple experiment. However, the results supported the view that loss of about $20 \%$ of total protein in a normal dog is associated with a redistribution of protein synthesis in such a way that visceral proteins (including albumin) are favoured at the expense of carcass proteins. This has been established subsequently by much more sophisticated studies (Clague, I98I).

\section{Semi-starved adult volunteers}

Two great studies of experimental undernutrition in normal men were carried out at the Carnegie Institute after the First World War (Benedict et al. 1919), and at the University of Minnesota after the Second World War (Keys et al. 1950). The second study was the more detailed, and was built on the experience gained from the first. The body-weight of thirty-two normal male volunteers was reduced by $24 \%$ of the initial value over a period of 24 weeks. Weight loss along a predetermined curve was achieved by altering the ration fed to each man to correct deviations from the curve week-by-week: the average intake for the whole group was $6.5^{6} \mathrm{MJ} / \mathrm{d}$, with about $50 \mathrm{~g}$ protein. After 24 weeks the average body-weight of the group was reduced from 69.34 to $53.63 \mathrm{~kg}$, the average body fat from 9.84 to $3.05 \mathrm{~kg}$, and consequently fat-free tissue was reduced from 59.50 to $50.5^{8} \mathrm{~kg}$. Thus, fat was reduced by $69 \%$ of the initial value, and non-fat tissue by only $15 \%$. However, body protein, judged by nitrogen balance, was reduced by about $26 \%$ of the initial value, and the decrease in muscle mass, indicated by the decrease in creatinine excretion, was about $38 \%$ (Keys et al. 1950). The discrepancy between the small loss of 'non-fat tissue', and the larger loss of total protein and muscle, is explained by the relative increase in water content which is a characteristic change associated with undernutrition.

This classical experiment shows that a group of normal men has survived an average loss of $6.8 \mathrm{~kg}$ of fat and $2.7 \mathrm{~kg}$ of protein, representing a total energy deficit of about $300 \mathrm{MJ}$. These results also suggest that muscle has contributed a disproportionately large part of the protein loss.

\section{Protein-energy malnourished children}

Young children have higher requirements for protein and energy relative to 
body-weight, than mature adults. Consequently, clinically important malnutrition is most commonly seen among young children. The characteristics of 248 malnourished children admitted to the Tropical Metabolism Research Unit in Jamaica between $195^{6}$ and 1962 are shown in Fig. 2. They were in age between 3 months and 2 years, and ranged from the clinical type called kwashiorkor, with marked oedema, dyspigmentation of skin and hair, and fatty infiltration of the liver, to marasmus characterized by severe wasting but without oedema or skin changes. All intermediate types also occurred. Of these 248 children thirty-seven died, and it was possible to classify the survivors into three groups according to their rate of recovery: thirty-four showed no definite improvement within 3 weeks of admission to hospital, seventy-five started to improve between $I$ and 3 weeks of admission, and 102 improved within the first week.

On the hypothesis that the cause of death in these children was related to protein depletion it might be expected that the most severely underweight children, or those with the most severe oedema, hypoproteinaemia or anaemia, would be those who died. However, a correlation analysis showed that the factors which were most closely related to survival were the serum sodium concentration and (in the eighty-four children for whom data were available) the serum bilirubin concentration (Garrow \& Pike, 1967). The relevant correlation coefficients are set out in Table $\mathrm{r}$. When facilities became available for measuring the total body potassium in these children it was evident that the low serum sodium concentration indicated profound potassium depletion, and treatment of these
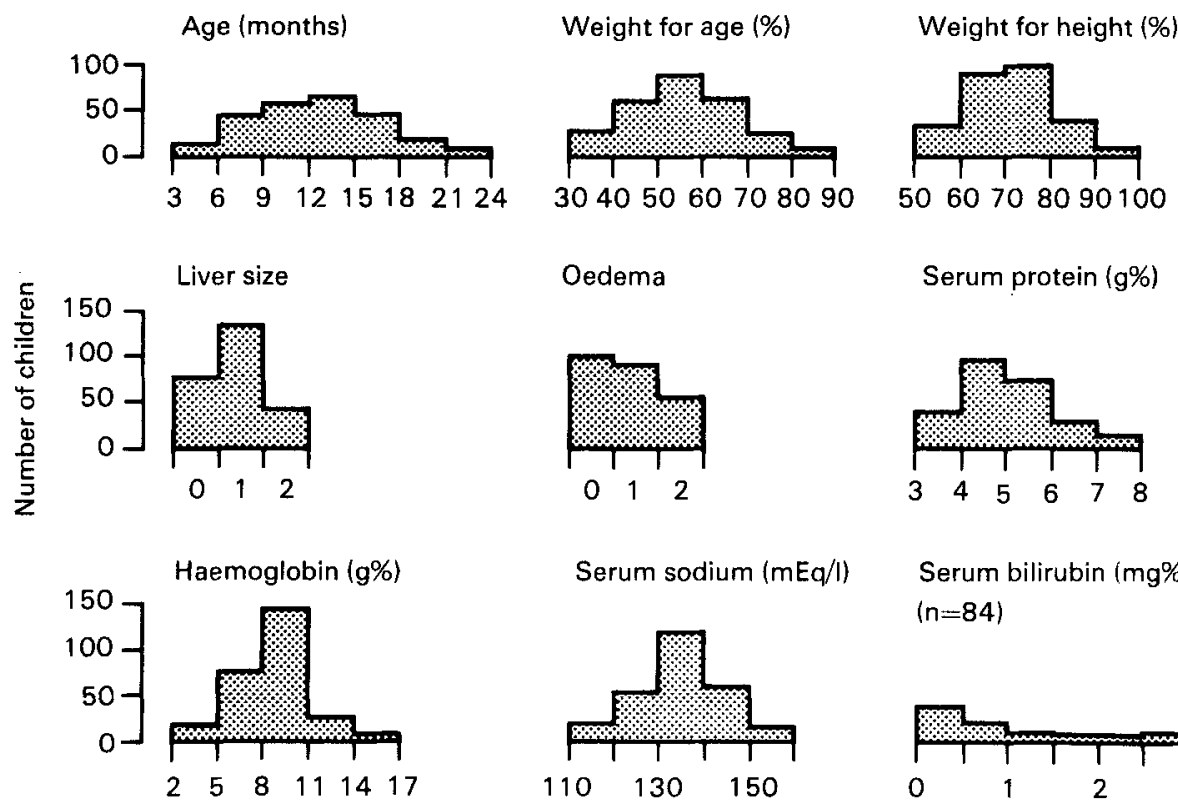

Oedema

Serum protein $(\mathrm{g} \%)$
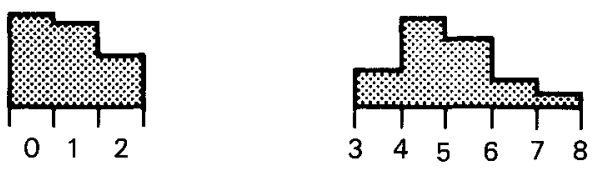

Serum sodium (mEq/l)
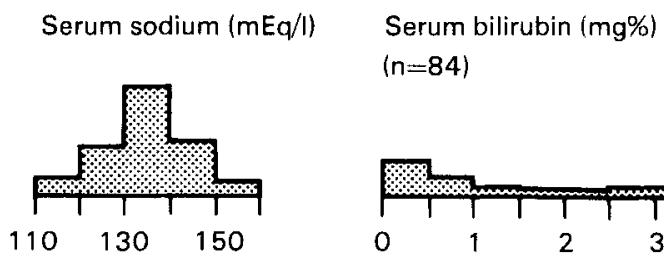

$(n=84)$

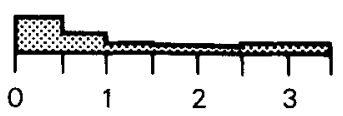

Fig. 2. Characteristics of 248 malnourished children admitted to the Tropical Metabolism Research Unit in Jamaica between 1956 and 1962 . Of these children thirty-seven died (Garrow \& Pike, I967). 
Table 1. Factors associated with survival, or speed of recovery, among 248 malnourished children under 2 years old, of whom thirty-seven died (Garrow ${ }^{\circ}$ Pike, 1967)

\begin{tabular}{|c|c|c|c|c|}
\hline \multirow[b]{2}{*}{ Variable } & \multicolumn{2}{|c|}{ Survival } & \multicolumn{2}{|c|}{ Recovery } \\
\hline & $r$ & $P$ & $r$ & $P$ \\
\hline Age & - & NS & 0.22 & $* * *$ \\
\hline Weight for age & $\ldots$ & NS & - & NS \\
\hline Weight for height & $\therefore$ & NS & - & NS \\
\hline Hepatomegaly & $\multimap .14$ & $\bullet$ & $\rightarrow 0.20$ & $\cdots$ \\
\hline Oedema & - & NS & -0.15 & - \\
\hline Plasma proteins & 0.17 & $\bullet$ & 0.24 & $\cdots$ \\
\hline Haemoglobin & - & NS & - & NS \\
\hline Serum $\mathrm{Na}$ & 0.26 & $\cdots *$ & 0.22 & $* *$ \\
\hline Bilirubin $(n 84)$ & -0.49 & $* * *$ & -0.50 & $* * *$ \\
\hline
\end{tabular}

children was best done by dealing with electrolyte disturbance and infection as first priorities; protein repletion was not an urgent matter.

\section{Massive weight loss in obese adults}

The thirty-two normal volunteers in the Minnesota experiment lost $24 \%$ of their initial weight and became emaciated having been subjected to an energy deficit of about $300 \mathrm{MJ}$. However, much greater energy deficits are frequently encountered during the treatment of severely obese adults. For example, Doré et al. (1982) reported a series of nineteen obese women who reduced body-weight from an average of $104.5 \mathrm{~kg}$ to $73.7 \mathrm{~kg}$ over a period of about $\mathrm{r}$ year. Total body potassium (an indicator of lean body mass) decreased from 3245 to $276 \mathrm{r}$ mmol K. If we make the assumption that all fat-free tissue in women contains $60 \mathrm{mmol} \mathrm{K} / \mathrm{kg}$ (Garrow, I981) the initial weight of $104.50 \mathrm{~kg}$ was made up of $50.42 \mathrm{~kg}$ fat and $54.08 \mathrm{~kg}$ fat-free tissue. After weight loss a similar calculation yeilds an estimated body composition of $27.7 \mathrm{I} \mathrm{kg}$ fat and $46.02 \mathrm{~kg}$ fat-free tissue. Thus the $29 \%$ decrease in body-weight was made up from a $15 \%$ decrease in fat-free tissue and a $45 \%$ decrease in fat. Assuming that fat-free tissue has an energy value of $4.2 \mathrm{MJ} / \mathrm{kg}$ this indicates an energy deficit of $888 \mathrm{MJ}$, or nearly three times that suffered by the Minnesota volunteers.

We are concerned with the magnitude of protein stores in the body, and the consequences of depleting these stores, so the question now arises: Were these women malnourished after weight loss? On the basis of clinical examination they appeared much fitter than they had been before weight loss, and certainly would not have been classified as malnourished. Perhaps a more appropriate criterion of nutritional status concerns their resting metabolic rate, since Keys et al. (1950) used a return to normal metabolic rate as a criterion of rehabilitation of their refed volunteers. After massive weight loss, resting metabolic rate is reduced compared with that observed before weight loss, but the metabolic rate of these patients after 
weight loss is not different from that of women of similar weight and body composition who have not lost weight (Dore et al. 1982). It appears, therefore, that severely obese adults can suffer a loss of some $15 \%$ of lean tissue without physiological disadvantage.

\section{Should protein reserves be sacrificed?}

The evidence, briefly reviewed above, indicates that the normal dog or adult human can lose about $20-25 \%$ of body protein without fatality, and the obese adult can lose $15 \%$ without inconvenience. Thus Cuthbertson's (1980) statement that 'the well-nourished casualty can survive for a few days on glucose and electrolytes ...' should be interpreted with 'few' meaning 30 or more, unless the injury has caused a particularly severe catabolic state. However, we are not concerned merely with the possibility of survival without parenteral replacement of nitrogen loss; of course this is not essential for survival, or the human race would by now be extinct. We need to decide in what circumstances it is best to sacrifice these protein reserves, and when it is preferable, and possible, to spare them. No clear answer to this question emerges from the literature. Subsequent papers in this symposium deal with the assessment of nutritional status, so we can judge how nearly these reserves have been exhausted. Obviously, with progressive depletion, the time must come when even the most conservative clinician is forced to try to replenish body protein stores, or at least to halt the drain upon them. This is a problem which is very familiar to those who have treated protein-energy malnutrition in children, and the temptation to undertake heroic protein repletion of emaciated children is very strong. However, over-vigorous repletion of malnourished children is associated with an increase in the mortality rate (Garrow et al. 1968) which might be predicted, since a child teetering on the brink of liver failure will find a large protein input an embarrassment rather than a help.

I wish to make one final point, which seems to receive little attention in the debate about the place of parenteral nutrition in the replenishment or sparing of protein reserves. If a patient is in a 'hypercatabolic state', as shown by a high $\mathrm{N}$ excretion in the urine, why is he not using all these endogenous amino acids for synthesis in high-priority proteins? Presumably there is something wrong with his synthetic machinery, due to toxaemia, limited energy supply, or some other factor. That being so, why is it reasonable to believe that a patient who is already awash with his own amino acids would benefit by receiving still more amino acids by the intravenous route?

\section{Summary}

Evidence from experimentally protein-depleted dogs and adult human volunteers shows that about $20-25 \%$ of total body protein can be lost without fatality. Muscle protein is used to protect visceral proteins. In obese adults $15 \%$ of body protein (together with a large amount of fat) can be lost without ill effects. Experience with malnourished children shows that rapid repletion of protein is not practicable or therapeutically helpful. Protein stores in the body undoubtedly exist, 
and are mobilized whenever the capacity for protein synthesis is inadequate to cover the rate of protein catabolism. It is not necessarily helpful, in such situations, to give more amino acids intravenously.

\section{REFERENCES}

Benedict, F. C., Miles, W. R., Roth, P. \& Smith, M. (1919). Human Vitality and Efficiency under Prolonged Restricted Diet. Carnegie Institution of Washington, Publ. no. 280.

Blackburn, G. L. \& Karminski, M. V. (1980). In Practical Nutritional Support, p. I66 [S. J. Karran and K. G. M. M. Alberti, editors]. Tunbridge Wells: Pitman Medical.

Clague, M. B. (1981). In Nitrogen Metabolism in Man, p. 525 [J. C. Waterlow and J. M. L. Stephen, editors]. London: Applied Science Publishers.

Cuthbertson, D. P. (1980). In Practical Nutritional Support, p. v [S. J. Karran and K. G. M. M. Alberti, editors]. Tunbridge Wells: Pitman Medical.

Dore, C., Hesp, R., Wilkins, D. \& Garrow, J. S. (1982). Hum. Nutr.: Clin. Nutr. 36C, 4 1.

Garrow, J. S. (I957). In Amino acid malnutrition: XIIIth Annual Protein Conference, p. I4 [W. H. Cole, editor]. New Brunswick: Rutgers Univ. Press.

Garrow, J. S. (1959). F. clin. Invest. 38, 124I.

Garrow, J. S. (I98I). Treat Obesity Seriously. Edinburgh: Churchill-Livingstone.

Garrow, J. S. \& Pike, M. C. (1967). Br. F. Nutr. 2 1, 155.

Garrow, J. S., Smith, R. \& Ward, E. E. (1968). Electrolyte Metabolism in Severe Infantile Malnutrition. Oxford: Pergamon Press.

Keys, A., Brozek, J., Henschel, A., Mickelsen, O. \& Taylor, H. L. (I950). The Biology of Human Starvation. Minneapolis: Univ. Minnesota Press.

Whipple, G. H., Miller, L. L. \& Robscheit-Robbins, F. S. (1947). F. exp. Med. 85, 277.

Wilmore, D. W. (1980). In Practical Nutritional Support, p. 322 [S. J. Karran and K. G. M. M. Alberti, editors]. Tunbridge Wells: Pitman Medical. 